\title{
Whole genome bisulfite sequencing of Medicago truncatula A17 wild type and Iss mutants
}

\author{
Nowlan H. Freese ${ }^{1}$, Elise L. Schnabel ${ }^{2}$ and Julia A. Frugoli ${ }^{*}$ (i)
}

\begin{abstract}
Objectives: Earlier work in our lab identified a spontaneous mutant (like sunn supernodulator-Iss) in Medicago truncatula, resulting in increased nodulation. Molecular genetic evidence indicated the phenotype was due to an unknown lesion resulting in cis-silencing of the SUNN gene. Altered methylation of the promoter was suspected, but analysis of the SUNN promoter by bisulfite sequencing at the time of publication revealed no significant methylation differences between the SUNN promoter in wild type and IsS plants. Using advances in methylome generation we compared the methylome of wild type and the Iss mutant in the larger $810 \mathrm{kB}$ area of the genome where lss maps.

Data description: The data show the distribution of types of methylation across the entire genome between A17 wild type and Iss mutants, the number of differentially methylated cytosines between genotypes, and the overall pattern of gene methylation between genotypes. We expect the wild type data will be especially useful as a reference for other investigations of methylation using $M$. truncatula.
\end{abstract}

Keywords: Methylation, Nodulation, Medicago truncatula, Autoregulation of nodulation, Iss

\section{Objective}

Legume plants regulate the number of nodules formed through a long distance signal transduction pathway that involves many genes [1]. Earlier work in our lab identified a spontaneous mutant in Medicago truncatula in the Jemalong cultivar, resulting in increased nodulation [2]. Molecular genetic evidence indicated the phenotype of the like-sunn-supernodulator (lss) mutant was due to an unknown lesion resulting in cis-silencing of the SUNN gene, which has a wild type sequence in lss mutants. Expression of SUNN in the shoots is critical to regulation of nodulation in the roots [3]. The lesion is mapped to an 810 kilobase area of the genome on chromosome 4, including the SUNN gene, but the nature of the lesion has

*Correspondence: jfrugol@clemson.edu

2 Department of Genetics \& Biochemistry, Clemson University, Clemson, SC 29634, USA

Full list of author information is available at the end of the article not been determined [2]. Altered methylation of the promoter was suspected, but analysis of the SUNN promoter by bisulfite sequencing at the time of publication revealed no significant methylation differences between the SUNN promoter in A17 wild type and lss plants [2]. Using genome capture combined with bi-sulfite sequencing, Satgé et al. [4] identified 474 regions that were differentially methylated during nodule development in M. truncatula and over 400 genes downregulated in plants with a mutant copy of the DEMETER demethylase gene. Because the lss lesion behaves like a paramutation, including reversion events [2], we decided to expand our bisulfite sequencing beyond the $S U N N$ promoter and compare the methylomes of the A17 wild type to the lss mutant.

\section{Data description}

\section{Whole genome bisulfite sequencing}

Data consist of sequencing results of two bisulfite libraries made from young leaves of individual 6-week-old

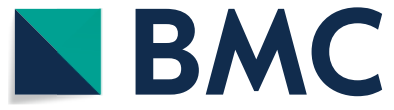

(c) The Author(s) 2020. This article is licensed under a Creative Commons Attribution 4.0 International License, which permits use, sharing, adaptation, distribution and reproduction in any medium or format, as long as you give appropriate credit to the original author(s) and the source, provide a link to the Creative Commons licence, and indicate if changes were made. The images or other third party material in this article are included in the article's Creative Commons licence, unless indicated otherwise in a credit line to the material. If material is not included in the article's Creative Commons licence and your intended use is not permitted by statutory regulation or exceeds the permitted use, you will need to obtain permission directly from the copyright holder. To view a copy of this licence, visit http://creativecommons.org/licenses/by/4.0/. The Creative Commons Public Domain Dedication waiver (http://creativecommons.org/publicdomain/zero/1.0/) applies to the data made available in this article, unless otherwise stated in a credit line to the data. 
Table 1 Overview of data files/data sets

\begin{tabular}{|c|c|c|c|}
\hline Label & Name of data file/data set & $\begin{array}{l}\text { File types } \\
\text { (file extension) }\end{array}$ & $\begin{array}{l}\text { Data repository and identifier (DOI or accession } \\
\text { number) }\end{array}$ \\
\hline Data file 1 [9] & Table summarizing WGBS alignment & (.pdf) & https://doi.org/10.17605/OSF.IO/B9CKM \\
\hline Data file 2 [9] & DMC data from A17 and Iss samples (CG and $\mathrm{CHG})$ & MS Excel file (.xIsx) & https://doi.org/10.17605/OSF.IO/B9CKM \\
\hline Data file 3 [9] & $\begin{array}{l}\text { DMR data from A17 and Iss samples (CG and } \mathrm{CHG} \text { ) } \\
\text { including nearest gene to DMR }\end{array}$ & MS Excel file (.x|sx) & https://doi.org/10.17605/OSF.IO/B9CKM \\
\hline Data file 4 [9] & $\begin{array}{l}\text { Visualization of genome wide differential methyla- } \\
\text { tion results }\end{array}$ & $(. \mathrm{pdf})$ & https://doi.org/10.17605/OSF.IO/B9CKM \\
\hline Data file 5 [9] & $\begin{array}{l}\text { Visualization of differential methylation of } \\
\text { Medtr4g070970 }\end{array}$ & $(. \mathrm{pdf})$ & https://doi.org/10.17605/OSF.IO/B9CKM \\
\hline Data set $1[10,11]$ & A17 sequence data & Sequence file (.fastq) & $\begin{array}{l}\text { SRA accession number (fastq.gz): https://identifier } \\
\text { s.org/insdc.sra:SRX4457708 }\end{array}$ \\
\hline Data set $2[10,12]$ & Iss sequence data & Sequence file (.fastq) & $\begin{array}{l}\text { SRA accession number (fastq.gz): https://identifier } \\
\text { s.org/insdc.sra:SRX4457709 }\end{array}$ \\
\hline
\end{tabular}

greenhouse grown Medicago truncatula A17 wild type and lss mutant plants (one of each). DNA was extracted using the DNeasy Plant Mini Kit (Qiagen). Bisulfite treatment of A17 and lss DNA was performed using the EZ DNA Methylation-Gold Kit (Zymo Research) according to manufacturer instructions. Whole genome bisulfite sequencing (WGBS) libraries were prepared using the Illumina TruSeq DNA Methylation library preparation kit. Library quality was assessed using an Agilent Bioanalyzer and quantitated using a Q-PCR kit from KAPA Biosystems following the manufacturer's instructions. Sequencing was performed on an Illumina HiSeq 2500 with the HiSeq Cluster Kit v4 $(1 \times 125$ bp single-read; see Data set 1 and Data set 2 for unaligned sequencing reads). Raw sequencing FASTQ files were trimmed to remove adapters, low-quality bases, and short reads using Trim Galore! v0.4.2 (Quality Phred score cutoff 5, min length 20). Alignment was carried out using Bismark v0.16.3 [5] and Bowtie2 v2.2.9 with $\mathrm{N}-1$ for increased sensitivity against the $M$. truncatula 4.0 genome. Duplicated sequences were removed with Picard MarkDuplicates v2.8.0 and alignments with MAPQ scores of 0 removed with Samtools v1.3.1. Sequencing and alignment results are summarized in data file 1 referenced in Table 1.

\section{Methylation analysis}

Methylation calling was performed using MethylDackel v0.2.1. Statistically significant differentially methylated cytosines (DMCs) were identified using the Bioconductor R package DSS v2.14.0 [6] (p.threshold 1e-5) (Data file 2 referenced in Table 1). Differentially methylated regions (DMRs) were also identified through DSS (pct. sig 0.5, minimum number of DMCs 10, $50 \mathrm{bp}$ minimum length, and DMRs merged if within $100 \mathrm{bp}$ ) (Data file 3 referenced in Table 1). There were 307 DMRs in the CG context and 772 DMRs in the CHG context. Displays of the number of DMCs in CG and CHG contexts, the number of DMRs identified by comparison of A17 and lss in CHG and CG contexts and the distributions of methylation across the exons and 1-kb flanking sequences for A17 and $l s s$ are graphically displayed in Data file 4 referenced in Table 1. Scripts used to analyze data and produce figures can be found at https://bitbucket.org/nfree se/medicagobseq. Bedtools v2.26.0 was used to associate DMRs with overlapping or closest gene (against $M$. truncatula MedtrA17_4.0 annotation) (Data file 3 referenced in Table 1) [7]. Methylation data was visualized using the Integrated Genome Browser in the area around the receptor protein kinase SUNN (Medtr4g070970) gene (Data file 5 referenced in Table 1) [8]. There was a single significant CG DMR within the first Medtr4g070970 exon. No DMRs were identified upstream or downstream within the CG or CHG context. The CG DMR identified within Medtr4g070970 displayed decreased methylation in the A17 sample.

\section{Limitations}

The data sets were generated without biological replicates and thus any comparison of the A17 and lss data is limited by a small sample size.

\section{Abbreviations \\ DMRs: Differentially methylated regions; DMCs: Differentially methylated cytosines; Iss like-sunn: șupernodulator; WGBS: Whole genome bisulfite sequencing.}

\section{Acknowledgements}

We acknowledge the David H. Murdock Research Institute Genomics Laboratory for generation of the sequence data.

\section{Authors' contributions}

ELS provided the biological material and examined the results, NHF generated the libraries, did the data analysis, and provided figures and text for the 
manuscript, JAF conceived the work and wrote the manuscript. All authors read and approved the final manuscript.

\section{Funding}

The design, tissue collection and sequencing was supported by NSF IOS 1444461 to Frugoli and the creation of the libraries and informatics analysis by NSF NPGI Postdoctoral fellowship 1523814 to Freese.

\section{Availability of data materials}

The data described in this Data note can be freely and openly accessed in the Sequence Read Archive (SRA) at https://identifiers.org/insdc.Sra:SRP155259

[10]. Please see Table 1 and reference list for details and links to the data.

\section{Ethics approval and consent to participate}

Not applicable.

\section{Consent for publication}

Not applicable.

\section{Competing interests}

The authors declare that they have no competing interests.

\section{Author details}

1 Department of Bioinformatics and Genomics, University of North Carolina at Charlotte, Kannapolis, NC 28081, USA. ${ }^{2}$ Department of Genetics \& Biochemistry, Clemson University, Clemson, SC 29634, USA.

Received: 18 December 2019 Accepted: 11 March 2020

Published online: 31 March 2020

\section{References}

1. Satge C, Moreau S, Sallet E, Lefort G, Auriac MC, Rembliere C, Cottret L, Gallardo K, Noirot C, Jardinaud MF, Gamas P. Reprogramming of DNA methylation is critical for nodule development in Medicago truncatula. Nat Plants. 2016:2:16166. https://doi.org/10.1038/nplants.2016.166.
2. Roy S, Liu W, Nandety RS, Crook A, Mysore KS, Pislariu C, Frugoli JA, Dickstein R, Udvardi M. Celebrating 20 years of genetic discoveries in legume nodulation and symbiotic nitrogen fixation. Plant Cell. 2020;32:15-41. https://doi.org/10.1105/tpc.19.00279.

3. Schnabel EL, Mukherjee A, Smith LS, Kassaw T, Long SR, Frugoli JA. The Iss supernodulation mutant of medicago truncatula reduces expression of the SUNN gene. Plant Physiol. 2010;154:139-1402. https://doi. org/10.1104/pp.110.164889

4. Penmetsa RV, Frugoli JA, Smith LS, Long SR, Cook DR. Dual genetic pathways controlling nodule number in Medicago truncatula. Plant Physiol. 2003:131:998-1008. https://doi.org/10.1104/pp.015677.

5. Krueger F, Andrews SR. Bismark: a flexible aligner and methylation caller for Bisulfite-Seq applications. Bioinformatics. 2011;27:1571-2. https://doi. org/10.1093/bioinformatics/btr167.

6. Park Y, Wu H. Differential methylation analysis for BS-seq data under general experimental design. Bioinformatics. 2016;32:1446-53. https:// doi.org/10.1093/bioinformatics/btw026.

7. Quinlan AR, Hall IM. IM, BEDTools: a flexible suite of utilities for comparing genomic features. Bioinformatics. 2010;26:841-2. https://doi.org/10.1093/ bioinformatics/btq033.

8. Freese $\mathrm{NH}$, Norris DC, Loraine AE. Integrated genome browser: visual analytics platform for genomics. Bioinformatics. 2016:32:2089-95. https:// doi.org/10.1093/bioinformatics/btw069.

9. Freese N, Schnabel E, Frugoli J. Whole genome bisulfite sequencing of Medicago truncatula A17 wild type and Iss mutants. Open Science Framework. 2019. https://doi.org/10.17605/OSF.IO/B9CKM.

10. Freese N, Schnabel E, Frugoli J. Whole genome bisulfite sequencing of Medicago truncatula A17 wild type and /ss mutants. INSDC. SRA SRP155259. 2019. https://identifiers.org/insdc.sra:SRP155259.

11. Bisulfite-Seq of Medicago truncatula: A17 leaves. NCBI Sequence Read Archive; 2019. https://identifiers.org/insdc.sra:SRX4457708.

12. Bisulfite-Seq of Medicago truncatula: LSS leaves. NCBI Sequence Read Archive; 2019. https://identifiers.org/insdc.sra:SRX4457709.

\section{Publisher's Note}

Springer Nature remains neutral with regard to jurisdictional claims in published maps and institutional affiliations.
Ready to submit your research? Choose BMC and benefit from

- fast, convenient online submission

- thorough peer review by experienced researchers in your field

- rapid publication on acceptance

- support for research data, including large and complex data types

- gold Open Access which fosters wider collaboration and increased citations

- maximum visibility for your research: over $100 \mathrm{M}$ website views per year

At BMC, research is always in progress.

Learn more biomedcentral.com/submissions 